\title{
Aminoglycoside-Inactivating Enzymes in Clinical Isolates of Streptococcus Faecalis
}

\author{
AN EXPLANATION FOR RESISTANCE TO ANTIBIOTIC SYNERGISM
}

\author{
Donald J. Krogstad, Thomas R. Korfhagen, Robert C. Moellering, Jr., \\ Christine Wennersten, and Morton N. Swartz, Department of Medicine, \\ Harvard Medical School and Massachusetts General Hospital (Infectious \\ Disease Unit), Boston, Massachusetts 02114 \\ Stanislaw Perzynski and Julian Davies, Department of Biochemistry, \\ University of Wisconsin, Madison, Wisconsin 53706
}

A в S T R A C T Clinical isolates of enterococci (Streptococcus faecalis) with high-level resistance to both streptomycin and kanamycin (minimal inhibitory concentration $>2,000 \mu \mathrm{g} / \mathrm{ml}$ ), and resistant to synergism with penicillin and streptomycin or kanamycin were examined for aminoglycoside-inactivating enzymes. All of the 10 strains studied had streptomycin adenylyltransferase and neomycin phosphotransferase activities; the latter enzyme phosphorylated amikacin as well as its normal substrates, such as kanamycin. Substrate profiles of the neomycin phosphotransferase activity suggested that phosphorylation occurred at the $3^{\prime}$-hydroxyl position, i.e., aminoglycoside 3 '-phosphotransferase. A transconjugant strain, which acquired high-level aminoglycoside resistance and resistance to antibiotic synergism after mating with a resistant clinical isolate, also acquired both enzyme activities. Quantitative phosphorylation of amikacin in vitro by a sonicate of the transconjugant strain inactivated the antibiotic, as measured by bioassay, and the phosphorylated drug failed to produce synergism when combined with penicillin against a strain sensitive to penicillin-amikacin synergism.

No differences were found in the sensitivity of ribosomes from a sensitive and resistant strain when exam-

This work was presented in part at the Interscience Conference on Antimicrobial Agents and Chemotherapy. October 1977, New York.

Dr. Perzynski's present address is the Institute of Biochemistry and Biophysics Polish Academy of Sciences, Warsaw, Poland. Dr. Krogstad's present address is the Microbiology Laboratory, Barnes Hospital, St. Louis, Mo. 63110. Address reprint requests to Dr. Moellering.

Received for publication 8 November 1977 and in revised form 31 March 1978. ined in vitro using polyuridylic acid directed $\left[{ }^{14} \mathrm{C}\right]-$ phenylalanine incorporation in the presence of streptomycin, kanamycin, or amikacin. Therefore, we conclude that aminoglycoside-inactivating enzymes are responsible for the aminoglycoside resistance, and resistance to antibiotic synergism observed in these strains.

\section{INTRODUCTION}

Enterococci are less sensitive to penicillin than other streptococci (1). Since the demonstration by Hunter in 1947 (2), and by Jawetz et al. in 1950 (3) that penicillin and streptomycin produce synergistic killing of enterococci, combinations of penicillin and an aminoglycoside have been used in the treatment of serious human enterococcal infections.

During the last $10-15 \mathrm{yr}$, centers in various parts of the United States $(4,5)$ and overseas $(6)$ have found $25-50 \%$ of clinical enterococcal isolates resistant to high levels of streptomycin and(or) kanamycin (minimal inhibitory concentration $>2,000 \mu \mathrm{g} / \mathrm{ml}$ ). Enterococci with high-level aminoglycoside resistance are refractory to synergism with penicillin and that aminoglycoside (7). Therefore, infections with such resistant organisms require treatment with penicillin and an aminoglycoside to which they are not highly resistant to produce synergism. As a result, we have been interested in studying the mechanism of this resistance to determine which aminoglycosides should be used in the treatment of enterococcal infections.

Because previous work has demonstrated that highlevel resistance and resistance to synergism were transferable by conjugation into a sensitive recipient strain (8), we have examined a series of Streptococcus fae- 
calis strains for aminoglycoside-inactivating enzymes: 10 clinical isolates with high-level resistance to streptomycin and kanamycin, a transconjugant strain produced by mating a sensitive recipient with one of the resistant strains, the sensitive recipient, and 5 sensitive clinical isolates were studied. A 45-Mdalton plasmid has been identified in five resistant isolates, which was not present in strains without high-level aminoglycoside resistance; this plasmid was also found in transconjugants of the sensitive recipient strain, after they had acquired high-level aminoglycoside resistance from resistant clinical isolates (8).

Additional experiments were designed to assess the role of enzymatic modification in the high-level aminoglycoside resistance and resistance to synergism found in clinical isolates of enterococci. To relate phosphorylation to drug resistance, amikacin was phosphorylated with a crude extract of the resistant transconjugant strain, and then used with penicillin in a synergism experiment against a strain sensitive to penicillinamikacin synergism. To evaluate the possible role of ribosomal aminoglycoside resistance, we isolated ribosomes from a sensitive and resistant strain, and measured the effect of streptomycin, kanamycin, and amikacin on protein synthesis in vitro. The, results of these studies and a discussion of the relationship between aminoglycoside-inactivating enzymes, aminoglycoside resistance, and resistance to synergism found in these strains form the basis of this report.

\section{METHODS}

Strains and media. Strains used were clinical isolates of $S$. faecalis obtained from blood cultures of patients hospitalized at the Massachusetts General Hospital between 1968 and 1976. Screening for high-level resistance to streptomycin and kanamycin was performed with a modified Steers replicator on brain heart infusion (BHI) plates containing 2,000 $\mu \mathrm{g} / \mathrm{ml}$ of antibiotic. The recipient strain of $\mathrm{S}$. faecalis, JH2-7, was kindly provided by Jacob and Hobbs (9) and is resistant to $25 \mu \mathrm{g} / \mathrm{ml}$ fusidic acid and $100 \mu \mathrm{g} / \mathrm{ml}$ rifampin. Cultures were grown at $37^{\circ} \mathrm{C}$ on a Gyrotory shaker (model G-10, New Brunswick Scientific Co., Inc., Edison, N. J.) set at 5 cycles/s.

Aminoglycoside-inactivating enzyme assays. Single colony isolates were inoculated into $\mathrm{BHI}$ broth and incubated overnight. The following morning, $0.5 \mathrm{ml}$ of overnight culture was added to $50 \mathrm{ml}$ of BHI broth and incubated with shaking for 6-7 h. Cells were harvested by centrifugation for $15 \mathrm{~min}$ at $4,500 \mathrm{~g}$ and $4^{\circ} \mathrm{C}$. The pellet was resuspended in $5.0 \mathrm{ml}$ of TMN buffer (10) and frozen overnight at $-20^{\circ} \mathrm{C}$. The next morning, after thawing at room temperature, cells were maintained in an ice bath and sonicated (sonifier cell disrupter, model W140 D, Heat Systems-Ultrasonics, Inc., Plainview, N. Y.) at a setting of 5.5 using three $30-\mathrm{s}$ bursts separated by $60-s$ pauses. Cell walls and other debris were removed by centrifugation at $4,500 \mathrm{~g}$ for $15 \mathrm{~min}$, and the supernate was used as a crude enzyme preparation in the aminoglycoside-inactivating enzyme assays.

On two occasions, sonic extracts were centrifuged at $100,000 \mathrm{~g}$ for $3 \mathrm{~h}$ at $8^{\circ} \mathrm{C}$ before use in the enzyme assays. Assays were performed according to the method of Benveniste and Davis
(11), with the following modification: aminoglycoside antibiotics were prepared at a concentration of $0.4 \mathrm{mg} / \mathrm{ml}$ in glassdistilled water. Thus, the concentration of aminoglycoside was $\cong 57 \mu \mathrm{g} / \mathrm{ml} ; 5 \mu \mathrm{l}$ of aminoglycoside solution was added to $10 \mu \mathrm{l}$ of buffer, $10 \mu \mathrm{l}$ of radioactive substrate, and $10 \mu \mathrm{l}$ of sonicated enzyme preparation in a total reaction volume of $35 \mu \mathrm{l}$. Enzyme activity in sonicates was quantitated relative to standard substrates, i.e., relative to neomycin for aminoglycoside 3 '-phosphotransferase activity and relative to streptomycin for streptomycin adenylyltransferase activity (11). Enzyme assays to determine substrate profiles were incubated for 20 min because preliminary studies showed that this period of time was within the linear portion of the curve obtained by plotting counts per minute versus time.

Isotopes were obtained from the ICN Pharmaceuticals, Inc., Irvine, Calif. These included $\left[\gamma-{ }^{32}\right.$ P]ATP $(1,000-2,000$ $\mathrm{Ci} / \mathrm{mmol})$, [U-1 $\left.{ }^{14} \mathrm{C}\right] \mathrm{ATP}(200-400 \mathrm{mCi} / \mathrm{mmol})$, and $\left[1{ }^{-14} \mathrm{C}\right]-$ acetyl coenzyme A $(30-50 \mathrm{mCi} / \mathrm{mmol})$. For use in enzyme assays these were diluted with distilled water and unlabeled ATP or acetyl coenzyme $A$ to specific activities of $65 \mathrm{mCi} /$ $\mathrm{mmol}$ of $\left[\gamma_{-}{ }^{32} \mathrm{P}\right] \mathrm{ATP} ; 20 \mathrm{mCi} / \mathrm{mmol}$ of $\left[\mathrm{U}-{ }^{14} \mathrm{C}\right] \mathrm{ATP}$; and 20 $\mathrm{mCi} / \mathrm{mmol}$ of $\left[1{ }^{14} \mathrm{C}\right]$ acetyl coenzyme A. ATP was obtained from Sigma Chemical Co., St. Louis, Mo., and trilithium acetyl coenzyme A from P-L Biochemicals, Inc., Milwaukee, Wis.

Purified aminoglycoside analogs were kindly provided by Dr. Kenneth Price, Bristol Laboratories Div., Bristol-Myers Co., Syracuse, N. Y., and included lividomycin A, butirosin $(85 \%$ A, $15 \%$ B), dideoxykanamycin B, and ribostamycin. Other antibiotics used in these experiments included: amikacin and kanamycin A (Bristol Laboratories Div., Bristol-Myers Co.); gentamicin, sisomicin, and netilmicin (Schering Corp., Schering-Plough Corp., Kenilworth, N. J.); streptomycin and tobramycin (Eli Lilly and Company, Indianapolis, Ind.); spectinomycin and neomycin (The Upjohn Co., Kalamazoo, Mich.).

Quantitative phosphorylation of aminoglycosides. Quantitative phosphorylation of amikacin and kanamycin was performed according to the method of Davies. ${ }^{1}$ Each flask contained the sonicated enzyme preparation $(2.0 \mathrm{ml})$, Tris buffer $(0.2 \mathrm{ml}$ of $1.0 \mathrm{M}, \mathrm{pH} 8.0), \mathrm{MgCl}_{2}(0.04 \mathrm{ml}$ of $1.0 \mathrm{M})$, aminoglycoside $(0.33 \mathrm{ml}$ of a $10.0-\mathrm{mg} / \mathrm{ml}$ solution), ATP $(0.1 \mathrm{ml}$ of $0.2 \mathrm{M}$ ATP in Tris buffer, $1.0 \mathrm{M}, \mathrm{pH} 7.6)$, dithiothreitol (Calbiochem, San Diego, Calif.; $0.03 \mathrm{ml}$ of $0.5 \mathrm{M}$ ), and glass-distilled water $(2.2 \mathrm{ml})$. All reagents except the enzyme preparation (cell sonicate) and aminoglycoside solution were sterilized before use by passage through a $0.45-\mu \mathrm{m}$ Millipore filter (Millipore Corp., Bedford, Mass.). The reaction mixture was incubated at $30^{\circ} \mathrm{C}$ in a water bath with slow shaking for $30 \mathrm{~h}$. Extra ATP $(0.1 \mathrm{ml}$ of $0.2 \mathrm{M}$ ATP $)$ was added to each flask after 6 and $18 \mathrm{~h}$ of incubation. The contents of each flask were checked for bacterial growth before use in synergism experiments. Biologic activity of the antibiotic in each flask was determined at the start and conclusion of the incubation using a bioassay, with Bacillus globigii as the indicator organism (12).

Synergism experiments. Synergism experiments were performed according to the protocol of Moellering et al. (13). Synergism was defined as a 100 -fold or greater increase in killing at $24 \mathrm{~h}$ by the combination of both drugs as compared to the most effective drug (penicillin) alone. The concentration of aminoglycoside used $(20 \mu \mathrm{g} / \mathrm{ml}$ for amikacin and dideoxykanamycin $B$ ) was less than the minimal inhibitory concentration, and did not interfere with growth of enterococci. Ribosomal studies. Cells were grown in broth, harvested in the early logarithmic growth phase, and washed twice in

${ }^{1}$ Davies, J. E. Unpublished data. 
TABLE I

High-Level Aminoglycoside Resistance, AminoglycosideModifying Enzymes, and Resistance to Antibiotic Synergism among Isolates of S. faecalis*

\begin{tabular}{|c|c|c|c|}
\hline & \multicolumn{2}{|c|}{ Clinical isolates } & \multirow{2}{*}{$\begin{array}{l}\text { Trans- } \\
\text { conjugan } \\
\text { strain }\end{array}$} \\
\hline & Resistant & Sensitive & \\
\hline \multicolumn{4}{|l|}{ High level resistance to } \\
\hline Streptomycin & + & - & + \\
\hline Kanamycin & + & - & + \\
\hline \multicolumn{4}{|l|}{$\begin{array}{l}\text { Aminoglycoside-modifying } \\
\text { enzymes }\end{array}$} \\
\hline $\begin{array}{l}\text { Streptomycin adenylyl- } \\
\text { transferase }\end{array}$ & + & - & + \\
\hline $\begin{array}{l}\text { Neomycin phosphotrans- } \\
\text { ferase }\end{array}$ & + & - & + \\
\hline \multicolumn{4}{|l|}{$\begin{array}{l}\text { Resistance to antibiotic } \\
\text { synergism }\end{array}$} \\
\hline Penicillin-streptomycin & + & - & + \\
\hline Penicillin-kanamycin & + & - & + \\
\hline
\end{tabular}

* High-level resistance equals minimal inhibitory concentration $>2,000 \mu \mathrm{g} / \mathrm{ml}$. 10 resistance clinical isolates, 5 sensitive clinical isolates, and 5 transconjugant strains, were examined for aminoglycoside resistance and aminoglycoside-modifying enzymes. Synergism studies were performed on 3 resistant isolates, 2 sensitive isolates, and 20 transconjugant strains.

TMN buffer with $0.5 \mathrm{mM}$ spermidine. They were then frozen at $-70^{\circ} \mathrm{C}$, and disrupted after thawing by grinding with twice their wet weight of alumina (14). An S-30 crude cell extract was prepared according to the method of Nirenberg (14), and used in subsequent studies. Protein synthesis was assessed using $\left[{ }^{14} \mathrm{C}\right]$ phenylalanine incorporation into trichloroacetic precipitable material with polyuridylic acid as messenger RNA in crude cell extracts (14). Aminoglycoside inhibition of protein synthesis was measured by the reduction in counts per minute due to addition of streptomycin, kanamycin, and amikacin (15).

\section{RESULTS}

Aminoglycoside-inactivating enzyme assays. All of the 10 clinical isolates of enterococci with high-level resistance to streptomycin and kanamycin had streptomycin adenylyltransferase and aminoglycoside phosphotransferase $3^{\prime}$ (neomycin phosphotransferase) activity. Neither enzyme was detected in the five sensitive clinical isolates nor in the sensitive recipient strain (Table I). However, after mating JH2-7 with a resistant clinical isolate, the transconjugant strain JH2-7 (pDR 1) (8) acquired both adenylyltransferase and phosphotransferase activities, as well as high-level resistance to streptomycin and kanamycin, and resistance to antibiotic synergism (Table I). Neither resistant nor sensitive clinical isolates had measurable acetyltransferase activity against streptomycin, neomycin, kanamycin, amikacin, or gentamicin.
The streptomycin adenylyltransferase activity present in resistant strains was not active against spectinomycin (Fig. 1). No adenylyltransferase activity was found in either resistant or sensitive strains when tested against neomycin, kanamycin, gentamicin, and tobramycin.

Substrate profiles of the aminoglycoside phosphotransferase $3^{\prime}$ (neomycin phosphotransferase) activity found in resistant strains are shown in Fig. 1. Neomycin, kanamycin, amikacin, ribostamycin, and butirosin (all of which have a $3^{\prime}$ hydroxyl group) were phosphorylated; gentamicin, tobramycin, netilmicin, and sisomicin (which do not have a $3^{\prime}$ hydroxyl group) were not (Fig. 1, data for netilmicin and sisomicin not shown). Lividomycin A, although it does not contain a $3^{\prime}$ hydroxyl group, was phosphorylated as well.

Examination of sonicates from resistant isolates after centrifugation for $3 \mathrm{~h}$ at $100,000 \mathrm{~g}$ to remove ribosomes revealed no loss of adenylyltransferase or aminoglycoside phosphotransferase $3^{\prime}$ (neomycin phosphotransferase) activity.

Quantitative phosphorylation of aminoglycosides. A sonicate obtained from the resistant transconjugant strain JH2-7 (pDR 1) inactivated all the amikacin present in the flask after $30 \mathrm{~h}$ of incubation (Table II). The same concentration of kanamycin exposed to the sonicate of JH2-7 (pDR 1) for $30 \mathrm{~h}$ was also inactivated. However, when an amikacin-containing flask was incu-
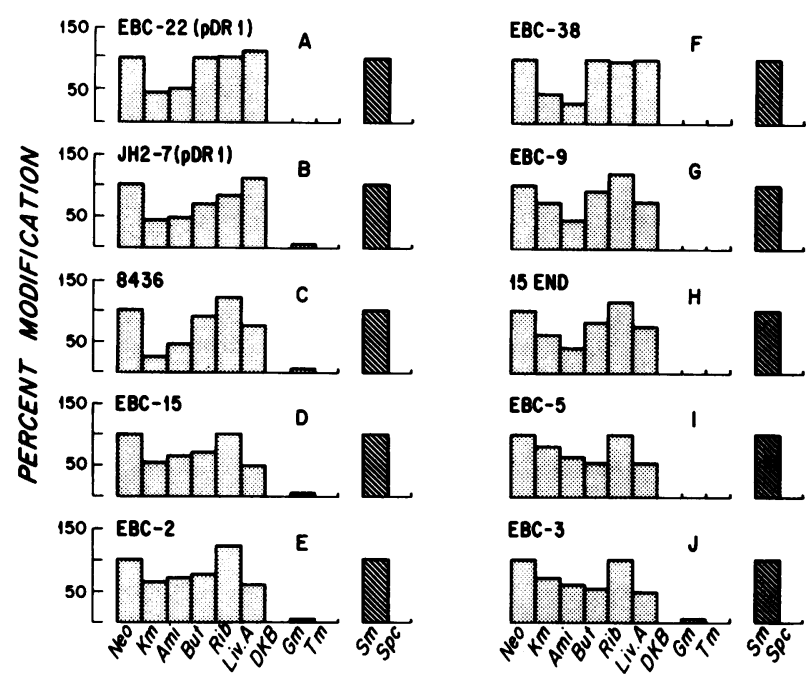

FIgURE 1 Substrate profiles of enzyme activities found in sonic extracts of clinical isolates of $S$. faecalis with highlevel resistance to streptomycin and kanamycin (minimal inhibitory concentration $>2,000 \mu \mathrm{g} / \mathrm{ml}$ ). Activities are calculated relative to neomycin for phosphotransferase (stippled area) and to streptomycin for adenylyltransferase (hatched area) activities as $100 \%$. Neo, neomycin; $\mathrm{Km}$, kanamycin $\mathrm{A}$; Ami, amikacin; But, butirosin; Rib, ribostamycin; Liv A, lividomycin A; DKB, dideoxykanamycin $B ; \mathrm{Gm}$, gentamicin; Tob, tobramycin; Sm, streptomycin; Spc, spectinomycin. 
bated with a crude extract of the sensitive recipient strain JH2-7 (before mating with the resistant clinical isolate), no significant loss of activity was detected by bioassay (Table II).

Synergism studies. When used with penicillin, phosphorylated amikacin (produced as described above) did not produce synergism against $\mathrm{JH2} 2$, the sensitive recipient strain, which is sensitive to penicillin-amikacin synergism (Fig. 2). The control for this experiment, which produced synergism, was penicillin with amikacin that had been incubated with the sonicate of the sensitive recipient strain, JH2-7 (Fig. 2). After substrate profiles had demonstrated that neither sensitive or resistant strains had enzymatic activity against dideoxykanamycin $B$, we studied a resistant clinical isolate, EBC-22 (pDR 1), and found that it was sensitive to penicillin-dideoxykanamycin B synergism although resistant to synergism with penicillin and kanamycin, amikacin, or streptomycin (Fig. 3).

Ribosomal studies. Ribosomes from a resistant clinical isolate, EBC-22 (pDR 1), were compared with those from the sensitive recipient strain, JH2-7. No significant differences were observed in the inhibition of radioactive phenylalanine incorporation into polypeptides by 3 aminoglycosides (streptomycin, kanamycin, and amikacin) over a wide range of concentrations (0.1-100 $\mu \mathrm{g} / \mathrm{ml}$ ) (Fig. 4).

\section{DISCUSSION}

Plasmid-mediated production of aminoglycosideinactivating enzymes has been well established among gram-negative organisms, and clearly confers resistance to clinically achievable concentrations of aminoglycosides which is transferable by conjugation $(16,17)$.

More recently, aminoglycoside-inactivating enzymes have been found among gram-positive bacteria as well. Courvalin and Davies (18) have reported a 3'-neomycin phosphortransferase, which also phosphorylates amikacin, in some strains of Staphylococcus aureus. However, the strains with this enzyme activity were still susceptible to amikacin.

Among enterococci, an S. faecalis strain from Jacob

TABLE II

Quantitative Phosphorylation of Amikacin

\begin{tabular}{lcc}
\hline & \multicolumn{2}{c}{$\begin{array}{c}\text { Amikacin concentration, } \\
(\mu \mathrm{g} / \mathrm{ml})^{*}\end{array}$} \\
\cline { 2 - 3 } Crude sonicate from & Zero time & Plus $30 \mathrm{~h}$ \\
\hline JH2-7 (pDR 1) & 88.0 & 0.0 \\
JH2-7 & 100.0 & 96.0 \\
\hline
\end{tabular}

* Amikacin levels were determined by bioassay (12) using a 10:1 dilution of the reaction mixture, (see text for details of incubation).

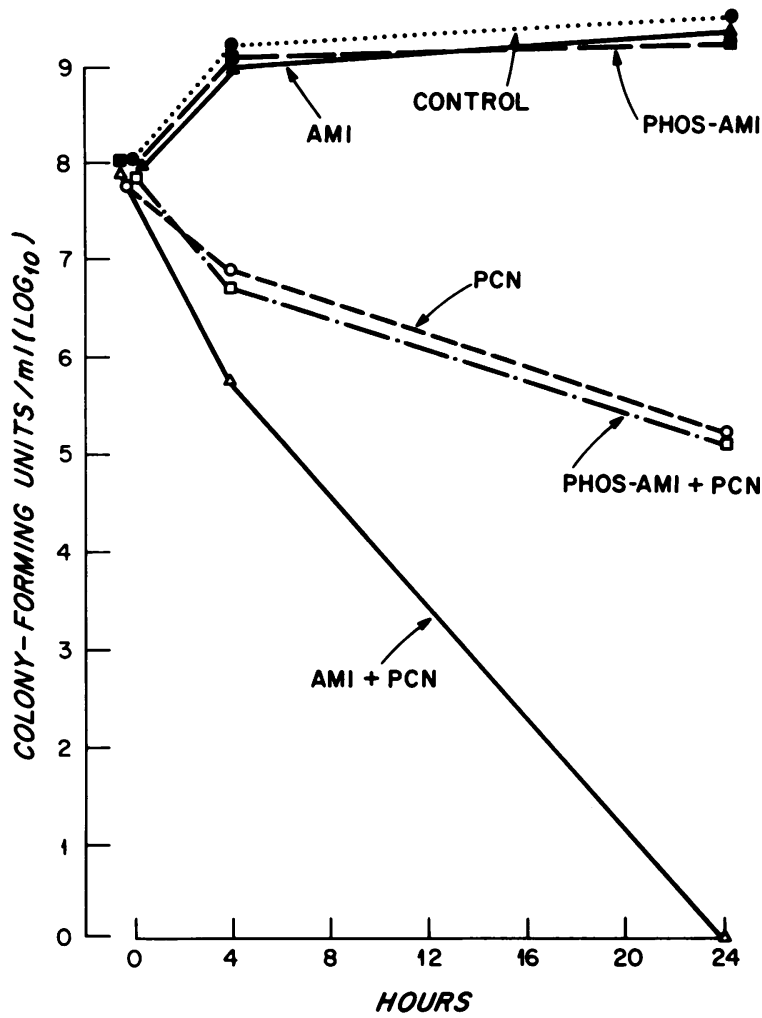

Figure 2 Effect of phosphorylated and unphosphorylated amikacin alone and in combination with penicillin against the sensitive recipient strain, JH2-7. $\mathrm{PCN}$, penicillin; AMI, amikacin; PHOS AMI, phosphorylated amikacin.

and Hobbs (9) with high-level streptomycin and kanamycin resistance has been found to have streptomycin adenylyltransferase and neomycin phosphotransferase activity by others ${ }^{2}$ and by ourselves. We have now described in this paper, clinical isolates with highlevel resistance to both drugs, resistance to antibiotic synergism, and both enzyme activities which transfer together by conjugation into a sensitive recipient strain. Because both enzymes are found in transconjugant strains which contain only the 45-Mdalton plasmid transferred from resistant clinical isolates (8), we have concluded that this plasmid controls the synthesis of both enzymes.

The association between high-level aminoglycoside resistance, resistance to penicillin-aminoglycoside synergism, and the presence of the two aminoglycoside-inactivating enzymes suggested, but did not prove a cause and effect relationship. The fact that phosphorylation of amikacin by a sonicate from a resistant enterococcus led to inactivation of the drug by bioassay suggested that the phosphorylated drug might also be inac-

\footnotetext{
${ }^{2}$ Courvalin, P. M., A. E. Jacob, and W. V. Shaw. Personal communication. Unpublished data.
} 


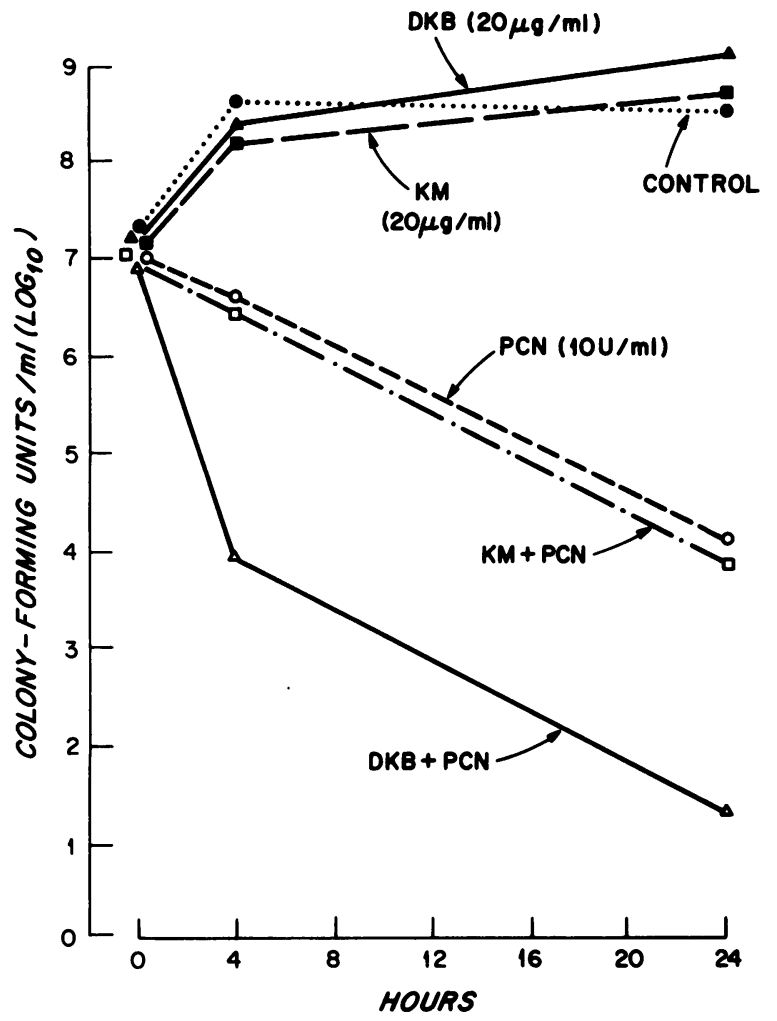

FIGURE 3 Effect of dideoxykanamycin B and kanamycin alone and in combination with penicillin against clinical isolate EBC-22 (pDR 1) which was sensitive to penicillindideoxykanamycin B synergism, but resistant to penicillinkanamycin synergism. DKB, dideoxykanamycin B; KM, kanamycin A.

tive against the enterococcus. However, because the indicator organism used in the bioassay was $B$. globigii, there was a theoretical possibility that the phosphorylated drug could have been active against enterococcus.

Therefore, a synergism experiment was designed, using penicillin and phosphorylated amikacin, to determine if phosphorylation of aminoglycosides accounted for the observed resistance to penicillin-aminoglycoside synergism seen with amikacin, kanamycin, and other aminoglycosides susceptible to phosphorylation. We chose amikacin because it is used more frequently today in clinical practice than either kanamycin or neomycin, and because previous work had demonstrated a 3'-phosphotransferase in clinical isolates of $S$. aureus which phosphorylated amikacin but did not confer amikacin resistance (18). The results of the synergism experiment demonstrated that phosphorylated amikacin does not produce synergism with penicillin against an enterococcal strain which is sensitive to penicillin-amikacin synergism (Fig. 2). Therefore, we have concluded that phosphorylated amikacin cannot synergize with penicillin against enterococci, and that phosphorylated neomycin and kanamycin are unlikely to do so. The exact mechanism(s) by which aminoglycoside-inactivating enzymes produce aminoglycoside resistance is not clear. Previous work using ribosomes isolated from Escherichia coli has shown that adenylylated streptomycin was not capable of inhibiting in vitro protein synthesis (19). Likewise, it has also been shown that purified (3') phosphorylated kanamycin does not inhibit ribosomal protein synthesis. ${ }^{1}$ Therefore, it seems likely that $\left(3^{\prime}\right)$ phosphorylated amikacin is also unable to inhibit protein synthesis.

However, recent work, especially from the laboratory of Bryan and Van Den Elzen (20), has suggested that resistance to aminoglycosides may result from decreased uptake across cell wall or cell membrane or decreased binding to the ribosome, as well as ribosomal resistance to the inhibition of protein synthesis. Therefore, additional studies will eventually be necessary to determine the relative importance of these several stages in enzymatically produced aminoglycoside resistance in enterococci as well as other bacteria.

Previous studies of streptomycin adenylyltransferase activity in gram-negative organisms have shown that the enzyme is characteristically active against spectinomycin, and inactive against certain blocked streptomycin derivatives such as $\mathrm{N}$-methyl-dihydrostreptomycin. Because the enzyme we have studied is inactive against spectinomycin (Fig. 1), it seems likely that adenylylation may be taking place on the streptidine ring at the 6 position as Suzuki et al. (21) has postulated in S. aureus, rather than at the $3^{\prime}$ position as it does among gram-negative bacteria. Because we have not yet been able to obtain either $N$-methyl-dihydrostreptomycin, or streptidine, we are presently unable to localize the site of adenylylation by these resistant enterococci.

Because aminoglycosides with a $3^{\prime}$ hydroxyl group (neomycin, kanamycin, amikacin, ribostamycin, and butirosin) were phosphorylated, and those without a 3' hydroxyl group were not (gentamicin, tobramycin, netilmicin, sisomicin, and dideoxykanamycin B), it

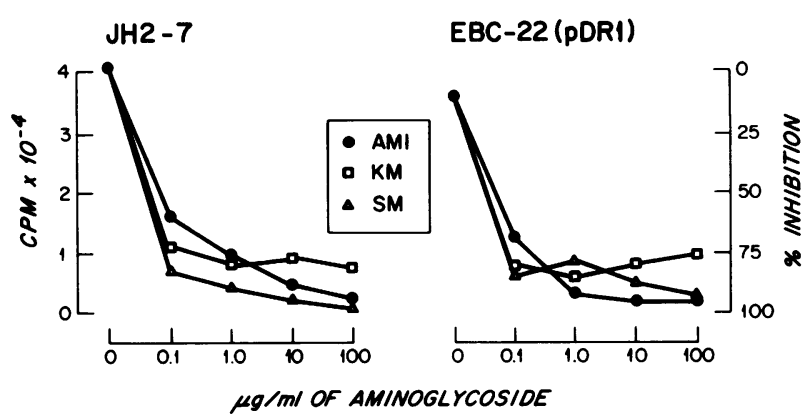

FIGURE 4 Inhibition of polyphenylalanine synthesis in cellfree extracts of S. faecalis strains JH2-7 and EBC-22 (pDR 1) by streptomycin, kanamycin, and amikacin. 
seemed most likely that phosphorylation was occurring at the $3^{\prime}$ hydroxyl position. The exception to this generalization was lividomycin $\mathrm{A}$, which does not contain a 3' hydroxyl group, but was phosphorylated by these strains and is also phosphorylated by gram-negative organisms with $3^{\prime}$ phosphotransferase activity (22).

Because previous studies of gram-negative organisms have shown that lividomycin $A$ is phosphorylated at the $5^{\prime}$ position by neomycin phosphotransferases I, and III (23), which characteristically phosphorylate at the $3^{\prime}$ position of neomycin, kanamycin, ribostamycin, and butirosin, but are inactive against amikacin (presumably due to steric hindrance), we assume this is also taking place in S. faecalis. Therefore, it appears that the phosphorylation of neomycin, kanamycin, and amikacin observed in these strains is most likely at the $3^{\prime}$ position, and that the enterococcal phosphotransferase is a type III (phosphorylates ribostamycin and butirosin), i.e., aminoglycoside phosphotransferase $3^{\prime}$ (III). Our results with dideoxykanamycin B strengthen the argument that phosphorylation is taking place at the $3^{\prime}$ position, and that phosphorylation produces resistance to antibiotic synergism. Dideoxykanamycin B differs from kanamycin A by the absence of hydroxyl groups at both the $3^{\prime}$ and 4 ' positions. Because an aminoglycoside with a hydroxyl group at the $4^{\prime}$ position but not at the $3^{\prime}$ position (tobramycin) is not phosphorylated by resistant strains, these results (penicillindideoxykanamycin $\mathrm{B}$ synergism against a resistant strain and lack of phosphotransferase activity against dideoxykanamycin $B$ among resistant clinical isolates) are consistent with a critical role of the $3^{\prime}$ hydroxyl group and with the hypothesis that phosphorylation at the $3^{\prime}$ position is necessary for biologic inactivation of these drugs. However, nucleo-magnetic resonance or other similar studies will eventually be required to document the structure of the phosphorylated aminoglycoside.

Because previous studies in our laboratory demonstrated that a mutant enterococcal strain with highlevel streptomycin resistance contained ribosomes that were relatively insensitive to the effects of streptomycin (15), we had originally speculated that the resistance in clinical enterococcal strains might also be due, at least in part, to aminoglycoside resistant ribosomes. However, comparative study of ribosomes from a sensitive strain and a highly resistant clinical strain which contained aminoglycoside-inactivating enzymes revealed no differences in the effect of streptomycin, kanamycin, or amikacin on the inhibition of protein synthesis, and we have concluded that the aminoglycoside resistance found in these strains is not due to resistant ribosomes. However, we have examined only strains with high-level resistance to both streptomycin and kanamycin, and these results do not exclude the possibility that some strains re- sistant to streptomycin alone may contain resistant ribosomes.

In addition to the site of adenylylation by streptomycin adenylyltransferase in resistant enterococcal strains, several other questions remain unanswered. Although the simplest explanation of our findings is that the plasmid codes for the synthesis of two aminoglycoside-inactivating enzymes, we cannot exclude the possibility that one or both gene(s) are situated on the chromosome, and that the plasmid regulates enzyme synthesis by coding for a derepressor(s). Similarly, because neither enzyme has been purified, we cannot exclude the possibility that more than one enzyme may be involved in producing the phosphotransferase activity we have found in crude extracts of resistant cells. The data reported here also do not localize the position of aminoglycoside-inactivating enzymes in enterococci, although activity remained in the supernatant fraction after centrifugation of a sonicate for $3 \mathrm{~h}$ at $100,000 \mathrm{~g}$.

Our results demonstrate that plasmid-mediated production of aminoglycoside-inactivating enzymes is responsible for high-level resistance to both streptomycin and kanamycin, and resistance to penicillinstreptomycin and penicillin-kanamycin synergism among some clinical isolates of enterococci. Streptomycin is inactivated by an adenylyltransferase; 2-deoxystreptamine aminoglycosides with a 3' hydroxyl group such as neomycin, kanamycin, and amikacin are inactivated by the phosphotransferase activity of resistant strains, and thus fail to produce synergism with penicillin. Conversely, aminoglycosides lacking a $3^{\prime}$ hydroxy group such as gentamicin, tobramycin, netilmicin, sisomicin, and dideoxykanamycin $B$ are not inactivated by the enzyme, and consistently produce synergism with penicillin against $S$. faecalis strains with or without high-level resistance to streptomycin and kanamycin. ${ }^{3}$

\section{ACKNOWLEDGMENTS}

We gratefully acknowledge several helpful discussions with Dr. Patrice M. Courvalin, and the assistance of Kathleen C. Thrasher, who performed the antibiotic assays, and the provision of aminoglycoside analogues by Dr. Kenneth Price. The secretarial assistance of Florence Larson is also gratefully acknowledged.

This paper was supported by National Institutes of Health grant 5 TO1 AI00215-15, 1132 A107061-01, National Institutes of Health grant AI 10076 to Dr. Davies, and by a grant from Bristol Laboratories.

\footnotetext{
${ }^{3}$ Since submission of this manuscript, we have become aware of the work of Dr. B. Slocombe who has also demonstrated transferable high level resistance to streptomycin and kanamycin in enterococci, and has identified the presence of a 3'-phosphotransferase which inactivates both kanamycin and amikacin in these strains. Dr. Slocombe, however, was unable to identify enzymes which inactivate streptomycin in his strains of enterococci (24).
} 


\section{REFERENCES}

1. Moellering, R. C., Jr., B. K. Watson, and L. J. Kunz. 1974. Endocarditis due to group D streptococci: comparison of disease caused by Streptococci bovis with that produced by enterococci. Am. J. Med. 57: 239-250.

2. Hunter, T. H. 1947. Use of streptomycin in treatment of bacterial endocarditis. Am. J. Med. 2: 436-442.

3. Jawetz, E., J. B. Gunnison, and V. R. Colman. 1950. The combined action of penicillin with streptomycin and chloromycetin on enterococci in vitro. Science (Wash. D. C.). 111: 254-256.

4. Iannini, P. B., J. Ehret, and T. C. Eickhoff. 1976. Effects of ampicillin-amikacin and ampicillin-rifampin on enterococci. Antimicrob. Agents Chemother. 9: 448-451.

5. Standiford, H. D., H. B. deMaine, and W. M. M. Kirby. 1970. Antibiotic synergism of enterococci. Arch. Intern. Med. 125: 255-259.

6. Ruhen, R. W., and J. W. Darrell. 1973. Antibiotic synergism against group $\mathrm{D}$ streptococci in the treatment of endocarditis. Med. J. Aust. 2: 114-116.

7. Calderwood, S. A., C. Wennersten, R. C. Moellering, Jr., L. J. Kunz, and D. J. Krogstad. 1977. Resistance to six aminoglycoside aminocyclitol antibiotics among enterococci. Prevalence, evolution and relationship to synergism with penicillin. Antimicrob. Agents Chemother. 12: 401-405.

8. Krogstad, D. J., T. R. Korfhagen, R. C. Moellering, Jr., C. Wennersten, and M. N. Swarz. 1978. Plasmid-mediated resistance to antibiotic synergism in enterococci. J. Clin. Invest. 61: 1645-1653.

9. Jacob, A. E., and S. J. Hobbs. 1974. Conjugal transfer of plasmid-borne multiple antibiotic resistance in Streptococcus faecalis var. zymogenes. J. Bacteriol. 117: 360-372.

10. Umezawa, H., M. Okanishi, S. Kondo, K. Hamana, R. Utahara, K. Maeda, and S. Mitsuhashi. 1967. Phosphorylative inactivation of aminoglycosidic antibiotics by Escherichia coli carrying $\mathrm{R}$ factor. Science (Wash. D. C.). 157: 1559-1561.

11. Benveniste, R., and J. Davies. 1973. Mechanisms of antibiotic resistance in bacteria. Annu. Rev. Biochem. 42: 471-506.

12. Winters, R. E., K. D. Litwack, and W. L. Hewitt. 1971. Relation between dose and levels of gentamicin in blood. J. Infect. Dis. 124(Suppl.): S90-S95.

13. Moellering, R. C., Jr., C. Wennersten, T. Medrek, and A. N. Weinberg. 1971. Prevalence of high-level resist- ance to aminoglycosides in clinical isolates of enterococci. Antimicrob. Agents Chemother. 1970: 335-340.

14. Nirenberg, M. W. 1964. Cell-free protein synthesis directed by messenger RNA. Methods Enzymol. 6: 17-23.

15. Zimmerman, R. A., R. C. Moellering, Jr., and A. N. Weinberg. 1971. Mechanism of resistance to antibiotic synergism in enterococci. J. Bacteriol. 105: 873-879.

16. Ozanne, B., R. Benveniste, D. Tipper, and J. Davies. 1969. Aminoglycoside antibiotics: inactivation by phosphorylation in Escherichia coli carrying $\mathrm{R}$ factors. J. Bacteriol. 100: 1144-1146.

17. Smith, D. H. 1969. R factors for aminoglycoside antibiotics. J. Infect. Dis. 119: 378-380.

18. Courvalin, P. M., and J. Davies. 1977. Plasmid-mediated aminoglycoside phosphotransferase of a broad substrate range that phosphorylates amikacin. Antimicrob. Agents Chemother. 11: 619-624.

19. Yamada, T., D. Tipper, and J. Davies. 1968. Enzymatic inactivation of streptomycin by $R$ factor-resistant Escherichia coli. Nature (Lond.) 219: 288-291.

20. Bryan, L. E., and H. M. Van Den Elzen. 1977. Effects of membrane-energy mutations and cations on streptomycin and gentamicin accumulation by bacteria: a model for entry of streptomycin and gentamicin in susceptible and resistant bacteria. Antimicrob. Agents Chemother. 12: 163-177.

21. Suzuki, I., N. Takahashi, S. Shirato, H. Kawabe, and S. Mitsuhashi. 1975. Adenylylation of streptomycin by Staphylococcus aureus: a new streptomycin adenylyltransferase. In Microbial Drug Resistance. S. Mitsuhashi and H. Hashimoto, editors. University Park Press, Baltimore, Md. 463-473.

22. Umezawa, Y., M. Yagisawa, T. Sawa, T. Takeuchi, and H. Umezawa. 1975. Aminoglycoside 3' phosphotransferase III, a new phosphotransferase: resistance mechanism. J. Antibiot. (Tokyo). 28: 845-853.

23. Umezawa, H., H. Yamamoto, M. Yagisawa, S. Kondo, T. Takeuchi, and Y-A Chabbert. 1973. Kanamycin phosphotransferase I: mechanism of cross resistance between kanamycin and lividomycin. J. Antibiot. (Tokyo). 26: 407-411.

24. Slocombe, B., 1978. Transmissible aminoglycoside resistance in strains of Streptococcus faecalis. In Current Chemotherapy. Proceedings of the 10th International Congress of Chemotherapy. Zurich, Switzerland. 2: 891-893. 